\title{
Exhaled carbon monoxide levels during treatment of acute asthma
}

\author{
M. Yamara, K. Sekizawa, S. Ishizuka, M. Monma, H. Sasaki
}

\begin{abstract}
Exhaled carbon monoxide levels during treatment of acute asthma. M. Yamaya, $K$. Sekizawa, S. Ishizuka, M. Monma, H. Sasaki. CERS Journals Ltd 1999.

ABSTRACT: Carbon monoxide is known to be present in measurable quantities in the exhaled air of normal subjects and at higher concentrations in asthmatic patients not treated with glucocorticoids.

To examine whether exhaled $\mathrm{CO}$ is useful in monitoring asthma control, time course changes in peak expiratory flow rate (PEFR) and exhaled $\mathrm{CO}$ concentration before and after treatment of acute asthma exacerbations were measured in 20 asthmatic patients. Exhaled $\mathrm{CO}$ was measured in triplicate by a portable $\mathrm{CO}$ analyser.

Exhaled $\mathrm{CO}$ was reproducible at all time points. Asthma exacerbations caused a fall in PEFR and a rise in exhaled CO (towards an average of 3.3 parts per million (ppm)) in all patients, and treatment with oral glucocorticoids reversed these changes in both parameters. An improvement of PEFR was closely associated with a reduction of exhaled CO (to an average of $1.5 \mathrm{ppm}$ ) after treatment. The maximal exhaled $\mathrm{CO}$ concentration significantly correlated with recovery time of PEFR after treatment with oral glucocorticoids $(\mathbf{p}<\mathbf{0 . 0 1})$.

The present study suggests that exhaled $\mathrm{CO}$ may be a useful noninvasive means of monitoring the control of asthma.

Eur Respir J 1999; 13: 757-760.
\end{abstract}

Dept of Geriatric Medicine, Tohoku University School of Medicine, Sendai, Japan.

Correspondence: H. Sasaki

Dept of Geriatric Medicine

Tohaku University School of Medicine

Aoba-ku Seiryo-machi 1-1

Sendai 980

Japan

Fax: 81227177186

Keywords: Airway inflammation

alveolar macrophages

epithelium

glucocorticoids

haem oxygenase

nitric oxide

Received: June 251998

Accepted after revision November 181998
Carbon monoxide is produced endogenously by the class of enzymes known collectively as haem oxygenase (HO) [1]. Two forms of HO have been characterized. Of these, HO- 1 is induced by oxidative stress $[2,3]$ and inflammatory cytokines $[4,5]$, and human airway epithelia exhibit HO-1 messenger ribonucleic acid (mRNA) and $\mathrm{HO}-1$ activity [6]. $\mathrm{CO}$ has been recovered in exhaled air from normal subjects and at higher levels from the exhaled air of patients with asthma [7]. Although significantly lower $\mathrm{CO}$ concentrations have been reported in exhaled air from asthmatic patients receiving glucocorticoid treatment than from asthmatic patients not receiving this therapy [7], the relationship between changes in exhaled CO concentrations and a therapeutic effect of glucocorticoids on the airways has not been shown in patients with acute asthma exacerbations. The time course changes in exhaled $\mathrm{CO}$ concentrations after treatment of acute asthma with oral glucocorticoids were therefore examined in a group of patients presenting with an asthma exacerbation.

\section{Materials and methods}

Asthmatic patients were recruited from patients attending the Tsukidate Municipal Hospital. Asthma was defined as a clinical history of intermittent wheeze, cough, chest tightness, or dyspnoea, and documented reversible airflow limitation either spontaneously or with treatment during the preceding year [8]. Before exacerbations of asthma, all the patients were usually in a stable condition. The patients were taking regular treatment with inhaled glucocorticoids (beclomethasone dipropionate $200 \mu \mathrm{g}$ daily), along with $\beta$ - adrenergic agonists on demand, and were categorized as moderate asthma [8]. Physical characteristics, pulmonary function test results, peak expiratory flow rate (PEFR) and exhaled $\mathrm{CO}$ during the stable period before exacerbation are shown in table 1 . All the asthmatic patients were nonsmokers and gave informed consent for participation in the study as approved by the Tohoku University Ethics Committee.

Exhaled CO was measured on a portable Bedfont EC50 analyser (Bedfont Technical Instruments Ltd., Sittingbourne, UK) using the method described by JARVIS et al. [9] in which subjects are asked to exhale fully, inhale deeply, and hold their breath for $20 \mathrm{~s}$ before exhaling rapidly into a disposable mouthpiece. This procedure was repeated three times, with 1 min of normal breathing between each repetition, and the mean value was used for analysis. Measurements of exhaled $\mathrm{CO}$ values were reproducible over a 3 -week period $(0.9 \pm 0.1$ parts per million $(\mathrm{ppm})$ before versus $1.0 \pm 0.1 \mathrm{ppm}$ after; $\mathrm{p}>0.50)$ in five nonsmoking control subjects (mean age $45 \pm 4$ yrs), and the variation

Table 1. - Physical characteristics and baseline pulmonary function test results

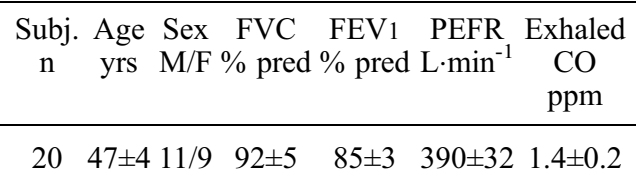

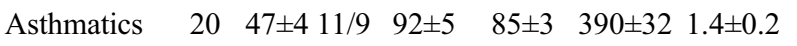

Values are mean \pm SEM. Subj.: subjects; M: male; F: female; FVC: forced vital capacity; FEV1: forced expiratory volume in one second; ppm: parts per million; PEFR: peak expiratory flow rate. 
between readings on separate days was small $(6.5 \pm 1.9 \%)$. Background $\mathrm{CO}$ values (0-1 ppm) were obtained prior to the subject readings.

To observe the relationship between ambient and exhaled $\mathrm{CO}$, the ambient levels of $\mathrm{CO}$ in a small room were varied from 1.0 to $8.1 \mathrm{ppm}$ using a mixture of $50 \mathrm{ppm}$ in air. After 5 min of normal breathing at each level of ambient $\mathrm{CO}$ (at least seven points), exhaled $\mathrm{CO}$ was measured as described above in the five nonsmoking control subjects. From linear regression analysis, the values of the regression slope and the regression intercept were obtained from each subject. Mean \pm SEM values were $1.0 \pm 0.1$ for the slope and $1.2 \pm 0.1 \mathrm{ppm}$ for the intercept. The values of the intercept did not differ from those of exhaled CO $(1.2 \pm 0.2$ ppm, $\mathrm{p}>0.50, \mathrm{n}=5$ ) measured during air breathing after subtracting the background level. Therefore, the exhaled $\mathrm{CO}$ concentration was determined by subtracting the background level from the observed reading in the following experiments as reported previously [9]. To avoid analysis with a value of exhaled $\mathrm{CO}$ concentration below $1.0 \mathrm{ppm}$, the background level was subtracted from the average value obtained from three sequential manoeuvres in each patient. The exhaled CO concentration values were always above $1.0 \mathrm{ppm}$ before subtracting the background level throughout the experiments. Prior to the start of the study, the analyser was calibrated with a mixture of $50 \mathrm{ppm} C O$ in air [9]. Exhaled $\mathrm{CO}$ concentration measured by the Bedfont EC50 analyser is reported to correlate closely with blood carboxyhaemoglobin concentration over the range of values encountered in smokers and in nonsmokers [10, $11]$.

PEFR was measured with a peak flow meter (Personal Best, Health Scan, Cedar Grove, NJ, USA). Exhaled CO and PEFR were measured before and at the onset of exacerbation of asthma, and 1,2, and 3 weeks after recovery. The 20 patients had presented themselves for emergency treatment due to exacerbations of asthma. They were assessed as to the severity of symptoms and physical examinations (e.g. breathlessness, talking, alertness, respiratory rate, wheeze, pulse), and complications including pneumothorax and pneumonia were examined. The arterial blood oxygen partial pressure in all patients was $>8.0 \mathrm{kPa}$ (60 mmHg). The inhalation of a $\beta$-adrenergic agonist had an incomplete or poor effect on symptoms and physical findings, and oral glucocorticoid treatment (prednisolone $40 \mathrm{mg}$ daily) was started in all patients according to a stepwise approach for asthma therapy [8]. PEFR and exhaled $\mathrm{CO}$ were measured as soon as possible after presentation and subsequently after the initiation of oral glucocorticoid treatment (prednisolone $40 \mathrm{mg}$ daily). Glucocorticoid therapy was continued until PEFR returned to the baseline value and recordings of PEFR and exhaled CO were performed every 7 days for 3 weeks. The recovery time of PEFR was defined as the period between the presentation of exacerbations of asthma and the time that PEFR returned to the baseline value of the stable condition.

To examine the relationship between upper respiratory tract infections (URTIs) and acute asthma, the asthmatic subjects were interviewed regarding the presence and severity of the following 10 symptoms: sneezing, nasal discharge, nasal congestion, malaise, headache, chills, fever, sore throat, hoarseness, and cough. Symptoms were rated for severity on a scale from $0-3$. A URTI was diagnosed if a total symptom score of $>5$ was obtained [12].
To isolate viruses from the asthmatic subjects with URTIs, 13 different viruses (influenza type A, B, and C, parainfluenza virus, adenovirus, rhinovirus, respiratory syncytial virus, mumps virus, poliovirus, Coxsackie B virus, herpes simplex virus, cytomegalovirus, and enterovirus) were screened for using throat swabs from each subject, and viruses were identified using methods described previously [13].

The values of exhaled $\mathrm{CO}$ concentration and PEFR were normally distributed. Therefore, the results are reported as mean \pm SEM. Statistical analysis was performed using a twoway analysis of variance (ANOVA), and followed by the Newman-Keuls test. Correlation between two parameters was examined by the Student's t-test. Significance was accepted at $\mathrm{p}<0.05$.

\section{Results}

Exhaled $\mathrm{CO}$ was reproducible in all asthmatic patients and values were similar among three sequential manoeuvres in asthmatic patients before exacerbations $(1.4 \pm 0.2$ ppm versus $1.4 \pm 0.2 \mathrm{ppm}$ versus $1.4 \pm 0.2 \mathrm{ppm}$ ), at the onset of exacerbations $(4.6 \pm 0.4 \mathrm{ppm}$ versus $4.6 \pm 0.4 \mathrm{ppm}$ versus $4.5 \pm 0.4 \mathrm{ppm}), 1$ week of recovery $(3.3 \pm 0.4 \mathrm{ppm}$ versus $3.2 \pm 0.4 \mathrm{ppm}$ versus $3.3 \pm 0.4 \mathrm{ppm}), 2$ weeks of recovery (1.6 $\pm 0.2 \mathrm{ppm}$ versus $1.6 \pm 0.2 \mathrm{ppm}$ versus $1.6 \pm 0.2 \mathrm{ppm})$, and 3 weeks of recovery $(1.5 \pm 0.2 \mathrm{ppm}$ versus $1.5 \pm 0.2 \mathrm{ppm}$ versus $1.5 \pm 0.2 \mathrm{ppm})$, respectively. The time course changes in exhaled $\mathrm{CO}$ and PEFR after treatment with oral glucocorticoids in all patients are shown in figure 1.
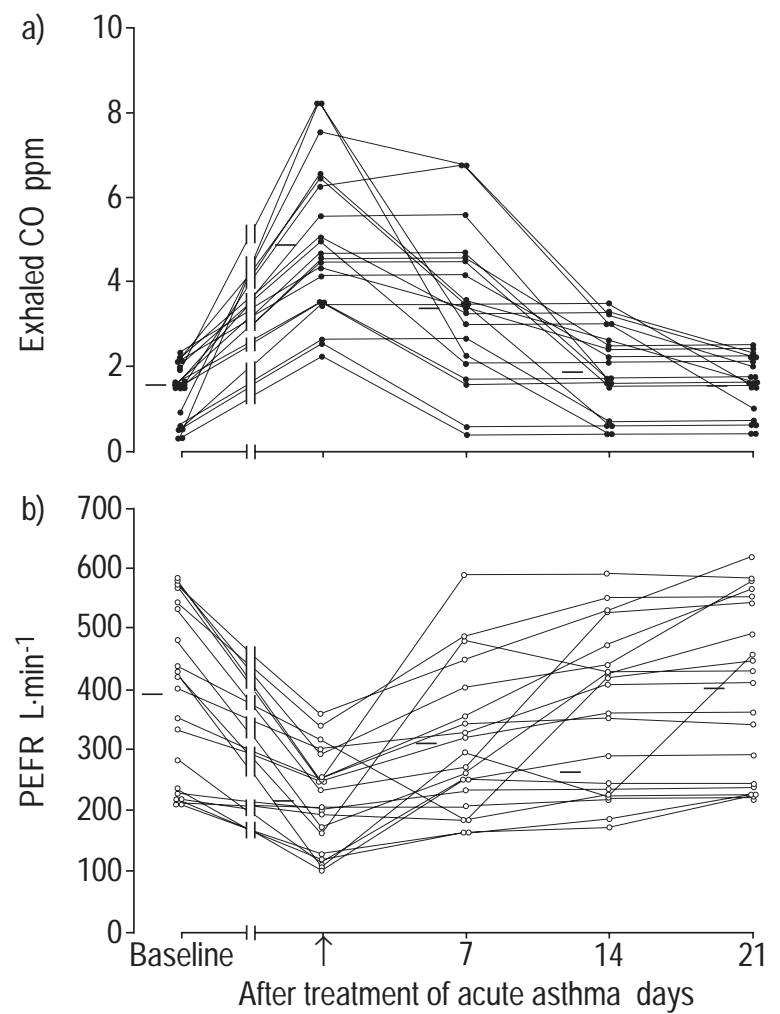

Fig. 1. - Time course changes in exhaled carbon monoxide concentrations (a) and peak expiratory flow rate (PEFR; b) in asthmatic patients before acute asthma exacerbations (baseline) and after treatment with oral glucocorticoids. ppm: parts per million. $\uparrow:$ the start of treatment of acute asthma exacerbations with oral glucocorticoids. Horizontal bars indicate mean values for each time-point. 
Acute asthma exacerbations caused increases in exhaled $\mathrm{CO}$ concentrations and decreases in PEFR in all patients. The mean exhaled $\mathrm{CO}$ concentration in asthmatic subjects at the baseline condition was $1.4 \pm 0.2 \mathrm{ppm}$. The exhaled $\mathrm{CO}$ was significantly higher at the start of glucocorticoid treatment for acute asthma $(4.6 \pm 0.4 \mathrm{ppm}, \mathrm{p}<0.01$, two-way ANOVA). Although there were some individual variations, treatment with oral glucocorticoids decreased exhaled CO concentrations in association with increases in PEFR ( $\mathrm{p}<$ 0.05 , in each case by two-way ANOVA). $\beta$-Adrenergic agonists did not alter the exhaled CO concentration (data not shown). Figure 2 summarizes the relationship between changes in exhaled CO and those in PEFR after treatment with oral glucocorticoids. Decreases in exhaled CO after treatment with oral glucocorticoids were coincident with an improvement of PEFR $(\mathrm{p}<0.05$, Student's t-test).

Although the maximal exhaled $\mathrm{CO}$ concentration did not correlate with the maximal fall in PEFR ( $p>0.20$, Student's t-test) (fig. 3a), a significant relationship was observed between the maximal exhaled $\mathrm{CO}$ concentration and recovery time of PEFR after treatment of acute asthma exacerbations with oral glucocorticoids $(\mathrm{p}<0.01$, Student's t-test) (fig. 3b).

All asthmatic patients had a total symptom score for URTIs of $>5(7.9 \pm 0.5, n=20)$. Influenza type A viruses were identified in 14 patients, and no viruses were detected in the other 6 patients at the onset of exacerbations of asthma.

\section{Discussion}

Glucocorticoid therapy is commonly employed to treat acute asthma exacerbations. In this study, an improved PEFR was found to be accompanied by a concomitant decrease in exhaled $\mathrm{CO}$ concentration in patients who needed emergency treatment for acute asthma. Furthermore, the maximal exhaled $\mathrm{CO}$ concentration correlates with recovery time of PEFR after treatment of acute asthma exacerbations with oral glucocorticoids. Thus, the present study extended previous findings [7] that the value of exhaled $\mathrm{CO}$ concentration may be used as an index of

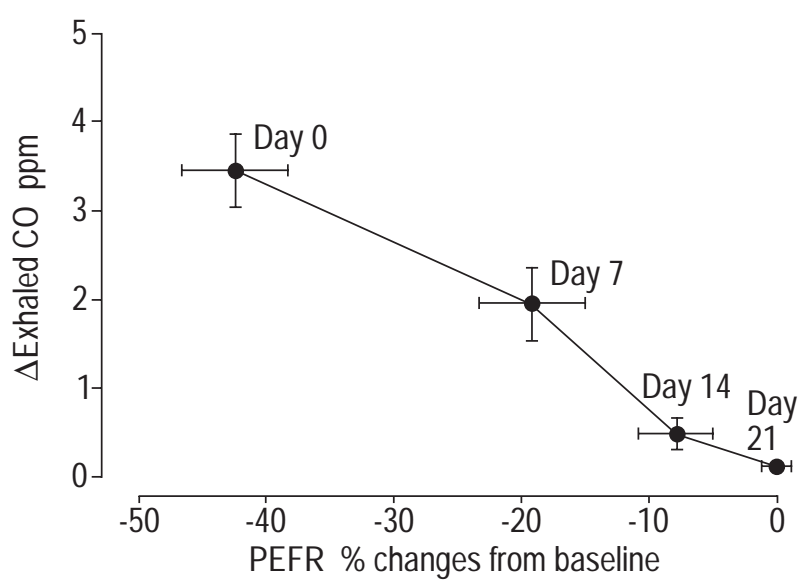

Fig. 2. - Relationship between changes in exhaled carbon monoxide from the baseline values and percentage changes in peak expiratory flow rate (PEFR) from the baseline values after treatment of acute asthma exacerbations with oral glucocorticoids. Results are reported as mean \pm SEM. The days represent those from the start of acute asthma treatment.
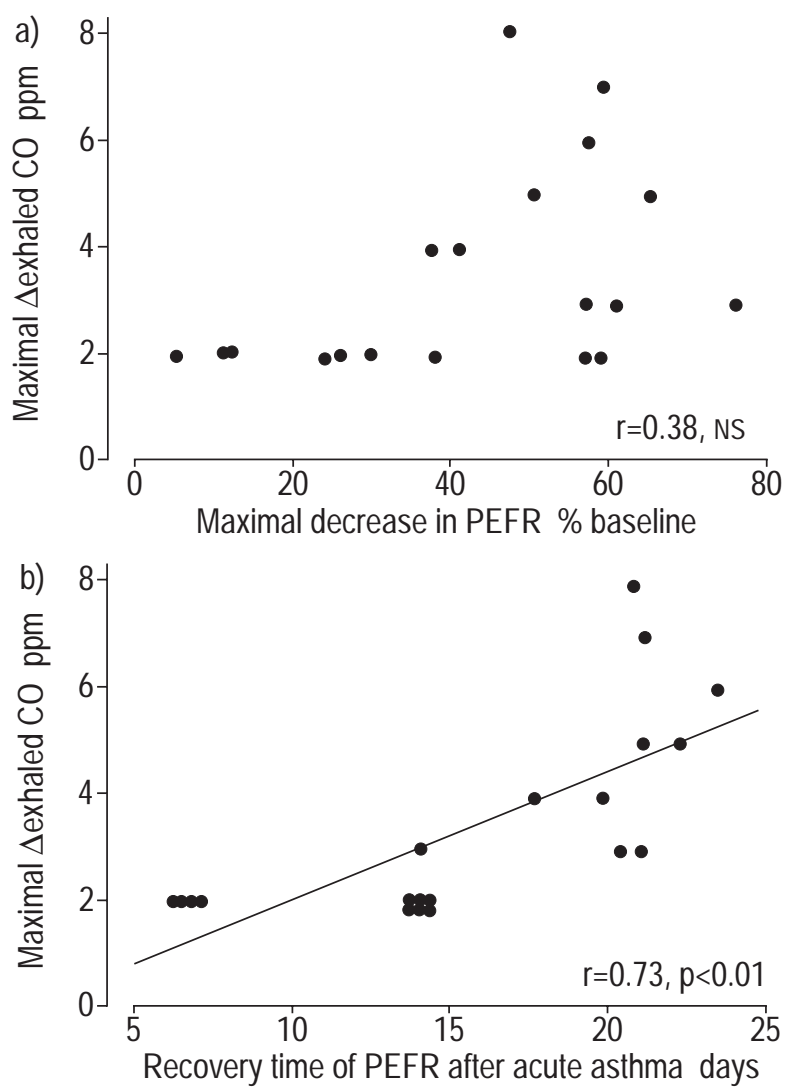

Fig. 3. - Relationship between the maximal changes in exhaled carbon monoxide concentration from the baseline values and the maximal decreases in a) peak expiratory flow rate (PEFR; percentage changes from the baseline values) and that between the b) maximal changes in exhaled $\mathrm{CO}$ concentration and the recovery time of PEFR after treatment of acute asthma exacerbations with oral glucocorticoids.

asthma severity and treatment efficacy. The levels of exhaled $\mathrm{CO}$ during the asthma exacerbations were consistent with those in asthma patients not receiving glucocorticoids [7].

It is likely that glucocorticoids reduce exhaled $\mathrm{CO}$ by inhibiting the induction of HO-1 in epithelial and inflammatory cells in the airways $[6,14]$. This may be by a direct effect on the HO promoter [5], or inhibition of the synthesis of pro-inflammatory cytokines $[4,5]$ and nitric oxide [15] that can induce HO-1 in asthma.

In the present study, all the patients had symptoms of URTIs and wheeze during the exacerbations of bronchial asthma. Viral infections may induce HO in a variety of cell types, including airway epithelial cells and macrophages [14] via the induction of pro-inflammatory cytokines [4] and NO [15]. These cytokines, including interleukin-1, interleukin-6 and tumour necrosis factor, are involved in asthmatic inflammation. Furthermore, asthmatic airways produce high levels of NO [16]. Therefore, both viral infection and asthmatic inflammation may upregulate HO-1 activity. Viral infection may induce airway inflammation and exacerbation of bronchial asthma, resulting in a rise in exhaled CO and a fall in PEFR in the present study.

In order to monitor the control of asthma it would be desirable to monitor inflammation in the airways. Monitoring of symptoms may be misleading, as bronchodilators relieve symptoms without treating the underlying 
inflammatory process. Airway hyperresponsiveness has been used as a marker of airway inflammation, but the changes in airway responsiveness after glucocorticoid therapy are modest and even when asthma is optimally controlled the values often remain abnormal $[17,18]$. More direct measurements of airway inflammation include bronchial biopsies, bronchoalveolar lavage and induced sputum. Bronchial biopsies and bronchial lavage are invasive procedures and are clearly unsuitable for clinically monitoring the airway inflammation of asthma [19]. Induced sputum is useful for assessing airway inflammation of asthma, but not all patients are able to produce satisfactory samples.

The measurement of exhaled CO may overcome some of these problems, as the measurement of exhaled $\mathrm{CO}$ can be easily performed in patients even when there is a severe airflow limitation. Furthermore, the measurement can be repeated in order to study the time course of any treatment, and the measurement is quantifiable. Although a previous study showed the relation between exhaled $\mathrm{CO}$ and the number of sputum eosinophils in asthmatic patients [7], further studies are needed to define the relationship between airway inflammation and exhaled CO.

Exhaled $\mathrm{CO}$ appears to be derived from an endogenous source, as none of the asthmatic patients were smokers, exsmokers or passive smokers, and background $\mathrm{CO}$ values were subtracted from the measured values. Although the source of the $\mathrm{CO}$ in exhaled air is uncertain, HO-1, the inducible form of $\mathrm{HO}$, is likely to be expressed in airway epithelial cells [6], endothelial cells [2] and alveolar macrophages [14].

The maximal rise in exhaled $\mathrm{CO}$ correlated with the recovery time of PEFR, but there was no significant relation between the maximal rise in exhaled $\mathrm{CO}$ and the maximal fall in PEFR after acute asthma exacerbations. KHARITONOv et al. [16] demonstrated no increase in exhaled NO in association with the early response in either single or dual responders after allergen challenge and during histamine-induced bronchoconstriction, indicating that bronchoconstriction itself does not have an effect on exhaled NO, a marker of airway inflammation. However, the late asthmatic response to allergen has been shown to be associated with elevated exhaled NO concentrations [16]. Therefore, maximal reduction of PEFR observed during an early period of acute asthma exacerbations may in part be due to bronchoconstriction. Thus, PEFR may not simply reflect the degree of airway inflammation during acute asthma exacerbations.

The present study suggests that exhaled $\mathrm{CO}$ may be a useful means of monitoring the control of airway inflammation of asthma. CO analysers are not widely used at the present time, but they are portable and not expensive. Therefore, it is possible to conceive the use of personal monitors in conjunction with home peak flow meters. Although an exhaled $\mathrm{CO}$ elevation was demonstrated in patients who needed emergency treatment for acute asth$\mathrm{ma}$, it is expected that exhaled CO levels may be elevated in even quite mild asthma with airway inflammation [19]. Thus, exhaled CO measurements may be useful in monitoring the control of asthma and the response to antiinflammatory treatments in individual asthmatic patients.

Acknowledgements. The authors thank G. Crittenden for English correction.

\section{References}

1. Maines MD. Heme oxygenase: function, multiplicity, regulatory mechanisms, and clinical applications. FASEB $J$ 1988; 2: 2557-2568.

2. Otterbein L, Sylvester SL, Choi AMK. Hemoglobin provides protection against lethal endotoxemia in rats: the role of heme oxygenase-1. Am J Respir Cell Mol Biol 1995; 13: 595-601.

3. Camhi SL, Alam J, Otterbein L, Sylvester SL, Choi AMK. Induction of heme oxygenase-1 gene expression by lipopolysaccharide is mediated by AP-1 activation. $\mathrm{Am}$ J Respir Cell Mol Biol 1995; 13: 387-398.

4. Cantoni L, Rossi C, Rizzardini M, Gadina M, Ghezzi P. Interleukin-1 and tumour necrosis factor induce hepatic haem oxygenase: feedback regulation by glucocorticoids. Biochem J 1991; 279: 891-894.

5. Lavrovsky Y, Drummond GS, Abraham NG. Downregulation of the human heme oxygenase gene by glucocorticoids and identification of $56 \mathrm{~b}$ regulatory elements. Biochem Biophys Res Commun 1996; 218: 759-765.

6. Yamada N, Yamaya M, Okinaga S, et al. Heme oxygenase 1 inhibits rhinovirus type 14 (HRV-14) infection and replication by cultured human tracheal epithelium. Am J Respir Crit Care Med 1997; 155: A943.

7. Zayasu K, Sekizawa K, Okinaga S, Yamaya M, Ohrui T, Sasaki H. Increased carbon monoxide in exhaled air of asthmatic patients. Am J Respir Crit Care Med 1997; 156: $1140-1143$.

8. Sheffer AL. International consensus report on the diagnosis and management of asthma. Clin Exp Allergy 1992; 22 (Suppl. 1): 1-72.

9. Jarvis MJ, Russell MAH, Saloojee Y. Expired air carbon monoxide: a simple breath test of tobacco smoke intake. Br Med J 1980; 281: 484-485.

10. Jarvis MJ, Belcher M, Vesey C, Hutchison DCS. Low cost carbon monoxide monitors in smoking assessment. Thorax 1986; 41: 886-887.

11. Irving JM, Clark EC, Crombie IK, Smith WCS. Evaluation of a portable measure of expired-air carbon monoxide. Preventive Med 1988; 17: 109-115.

12. Jackson GG, Dowling HF, Spiesman IG, Boand AV. Transmission of the common cold to volunteers under controlled conditions: I. The common cold as a clinical entity. Arch Intern Med 1958; 101: 267-278.

13. Numazaki Y, Oshima T, Ohmi A, et al. A microplate method for isolation of viruses from infants and children with acute respiratory infections. Microbiol Immunol 1987; 31: 1085-1095.

14. Fukushima T, Okinaga S, Sekizawa K, Ohrui T, Yamaya $\mathrm{M}$, Sasaki H. The role of carbon monoxide in lucigenindependent chemiluminescence of rat alveolar macrophages. Eur J Pharmacol 1995; 289: 103-107.

15. Kim YM, Bergonia HA, Müller C, Pitt BR, Watkins WD, Lancaster JR. Loss and degradation of enzyme-bound heme induced by cellular nitric oxide synthesis. J Biol Chem 1995; 270: 5710-5713.

16. Kharitonov SA, O'Connor BJ, Evans DJ, Barnes PJ. Allergen-induced late asthmatic reactions are associated with elevation of exhaled nitric oxide. Am J Respir Crit Care Med 1995; 151: 1894-1899.

17. Barnes PJ. Effect of corticosteroids on airway hyperresponsiveness. Am Rev Respir Dis 1990; 141: S70-S76.

18. Juniper EF, Kline PA, Vanzieleghem MA, Ramsdale EH, O'Byrne PM, Hargreave FE. Effect of long-term treatment with an inhaled corticosteroid (budesonide) on airway hyperresponsiveness and clinical asthma in nonsteroid dependent asthmatics. Am Rev Respir Dis 1990; 142: 832-836.

19. Djukanovic R, Roche WR, Wilson JW, et al. Mucosal inflammation in asthma. Am Rev Respir Dis 1990; 142: 434-457. 